\title{
As estações climatericas brasileiras
}

Appello e contribuição para o seu estudo, pelo doutorando Eurico Branco Ribeiro.'

$\mathbf{M}$

UITAS vezes, entre nós, o medico se vê atrapalhado para indicar um clima que convenha ao seu cliente. Não que nos faltem bons climas: temol-os tão invejaveis em quantidade como na qualidade.

O que nos falta, porém, é conhecel-os melhor, para recommendal-os com segurança.

O nosso medico geralmente sáe das faculdades sem noção alguma de climatologia, de sorte que, quando, na vida pratica, se lhe depara uma opportunidade de recorrer a um determinado clima incluso nas prescripções classicas, fica deveras embaraçado e norteia-se mais pelos diz-que-disse da consagração publica do que por dados meteorologicos devidamente interpretados.

Não vae nessa critica a pretenção de sermos conhecedores dos mysterios da climatologia, mas sim um sentimento de appello aos nossos institutos scientificos no sentido de promoverem, com o auxilio, naturalmente, das repartições publicas competentes, o estudo e a classificação dos pontos do nosso territorio recommendaveis para estações climatericas.

E' escusado exaltar o valor pratico de um tal empreendimento. A classe medica, que, nesse particular, se decide por predilecções toda pessoaes, teria, com isso, uma orientação segura para encontrar o effeito das indicações de clima. E quem mais beneficios colherá, certamente é o publico, elle que tanta vez se vê prejudicado com estações climatericas indicadas sem a devida segurança.

Um tal estudo não se fará em dois dias e por obra de uma só pessoa. E' preciso, pois, que cada qual apresente os resultados da sua observação ou os dados fidedignos que encontrar, afim de se reunirem elementos para a obra meritoria de classificação que aos nossos institutos scientificos compete promover.

E' por isso que nos aventuramos a dar á publicidade um trecho do trabalhinho por nós apresentado, em 1926, á cadeira de Hygiene 
da Faculdade de Medicina de São Paulo sobre as condições sanitarias da cidade de Guarapuava, nossa terra natal, situada em pleno coração do Paraná.

Nesse trecho, colligimos os dados climatericos que nos foi possivel obter, e, baseado nelles, tiramos algumas conclusões e fizemos uma serie de comparações, que bem justificam a fama de que gosa o clima guarapuavano, aliás consagrado com estas palavras do Visconde de Taunay, que não nos cançamos de citar:

"Que ar puro, leve, perfumado, ali se respira! Como que os meus pulmões ainda conservão essa deliciosa impressão! A todos digo sempre: em dous logares do Mundo respirei com verdadeira delicia, como que mergulhado em ambiente novo - Guarapuava e Napoles"

Não nos extendemos, no referido trabalhinho, ás indicações medicas do clima guarapuavano. Tampouco chegaremos a ellas, agora: o nosso intuito, como dissemos, é apresentar dados com que collaboremos, ainda que em minima parcella, com os futuros classificadores das estações climatericas brasileiras.

Eis o excerpto:

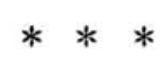

Guarapuava está localizada em plena zona temperada.

Procurando dados que nos permittissem referir a sua situação geographica, encontrámos os seguintes:

Latitude, 25 23'36" sul; longitude, $8^{\circ}$ 16'58" oeste do Rio de Janeiro; altitude, 1.095 metros - segundo Alcibiades Plaisant.

Latitude, $25^{\circ} 24^{\prime} \mathrm{sul}$; longitude, $51^{\circ} 25^{\prime}$ oeste de Greenwich e $8^{\circ} 15^{\prime}$ oeste do Rio; altitude, 1.095 metros - segundo o "Boletim Meteorologico" relativo a 1885 .

Latitude, $25^{\circ} 23^{\prime} 36^{\prime \prime} 5 \mathrm{sul}$; longitude, $8^{\circ} 16^{\prime} 58^{\prime \prime}$ oeste do Rio; altitude, 1.117,50 metros - segundo a these do dr. João Kolb (Mackenzie College).

Latitude, $25^{\circ} 23^{\prime} 36^{\prime \prime}$ sul; longitude, 51 $45^{\prime} 07^{\prime \prime}-3$ horas 27 oeste de Greenwich; altitude, 1.119,37 metros - segundo os dados que nos forneceu a Estação Climatologica de Guarapuava.

Esses numeros, ligeiramente discordes, são unanimes, porém, em affirmar que Guarapuava está situada na zona temperada e possue um clima de altitude, pois que, em tal latitude, devendo ser de 4.200 metros, approximadamente, o limite de passagem para as neves eternas, os "climas de altitude" começam em altitude quatro vezes menor ou seja a 1.050 metros, e vão até o dobro desse algarismo, com o qual se iniciam os chamados "climas de montanha"

Para se ter idéa da salubridade de Guarapuava, a essas classificações se junte a resultante destes dados fornecidos pelo thermometro: oscillando a temperatura media annual entre $16^{\circ}$ e $17^{\circ}$, Guarapuava 
está entre os menos calidos dos climas quentes; como a differença entre as temperaturas médias do mês mais quente e do mês mais frio varia, em periodos de cinco annos, entre $8^{\circ}, 8$ e $9^{\circ}, 2$, Guarapuava merece estar ao lado dos logares de clima constante ou regular.

Em resumo, technicamente falando, Guarapuava possue o "clima suave das zonas temperadas"

Não podia ter melhor classificação.

Os dados meteorologicos que a seguir reproduzimos servirão de contraprova a tão sorridentes conclusỗes.

Para que se possa aquilatar do valor do clima de Guarapuava, sabido que a humidade relativa, a abundancia das chuvas, a velocidade dos ventos e o numero das tempestades crescem geralmente com a altitude, comparemos os dados da nossa cidade com os de outras de altitude menor, nas quaes, em vista de tal condição, as verificações climatericas são evidentemente inferiores.

Principiemos pela humidade relativa. Em 1921, a media verificada para Guarapuava foi de $74,4 \%$; em 1922 , de $80,3 \%$; em 1923 , de $71,4 \%$; em 1924 , de $76,9 \%$ e em 1925 , de $75,3 \circ 0^{\circ}$ - o que dá uma média de $75,66 \%$ no quinquennio. No quinquennio de 1885 e 1889 ella fôra de $77,1 \%$. Consideremos a media desses numeros, ou seja $76,38 \%$.

Vejamos agora a quantidade de chuva: $1.641,6 \mathrm{~mm}$. em 1921; $2.155,6 \mathrm{~mm}$. em 1922; 1.952,9 mm. em 1923; $1.245,9 \mathrm{~mm}$. em 1924; e $1.420,0 \mathrm{~mm}$. em 1925 - media: $1.683,2 \mathrm{~mm}$.

São Paulo, situada a 740 metros de altitude, accusa uma média geral de $79 \%$ de humidade relativa com $1.357 \mathrm{~mm}$. de chuva por anno. Ora, em Guarapuava cáe mais chuva e a humidade é menor, donde se conclue que o clima é mais secco, a evaporação se fazendo com mais facilidade.

Botucatú, apontado como um dos melhores climas do Estado de São Paulo, a 800 metros de altitude, apresenta $77 \%$ de humidade relativa e apenas $1.428 \mathrm{~mm}$. de chuva por anno.

Em Campos do Jordão, onde, na média, chove tanto como em Guarapuava, a humidade relativa é de $79 \%$, devendo-se levar em conta, porém, que o seu posto climatologico está a 1.595 metros de altitude. Comtudo, a denominada "Suissa Paulista" é mais humida do que Guarapuava. E a localidade central do Paraná leva-lhe ainda outras vantagens: emquanto em Campos do Jordão a velocidade media dos ventos é "de pouco mais de 4 metros por segundo", em Guarapuava, onde raramente se registam tempestades, a velocidade media é apenas de 3,48, havendo extensos periodos de calma.

Se a nebulosidade de Guarapuava $(5,88)$ é maior que a de Compos do Jordão $(5,1)$ - a de São Paulo é 6,2 - a estação climaterica paulista tem 2.343 horas de insolação, emquanto a cidade paranaense 2.369,28 (media de cinco annos). A cidade de São Paulo regista ape- 
nas 2.078 horas de insolação por anno. Davos-Platz, estação suissa para tuberculosos, accusa sómente 1.844 horas de insolação e a sua humidade relativa é de $78 \%$, comquanto a chuva e a neve apenas assignalem $897,7 \mathrm{~mm}$. annualmente.

Quanto á temperatura, é ella mais agradavel em Guarapuava, onde a media annual oscilla entre $16^{\circ}$ e $17^{\circ}$, do que em Campos do Jordão, onde a media é de $12^{\circ}, 8$. A differença entre os extremos absolutos da temperatura é sensivelmente igual: Campos do Jordão, $36^{\circ}, 8$ (maxima $28^{\circ} 8$ em 18-4-1910 e minima - $8^{\circ}$ em 25-7-1923); e Guarapuava 370,3 (maxima, 31 ${ }^{\circ}, 8$ em 15-12-1924 e minima - 50,5 em 8-6-1921). Emquanto em Campos do Jordão a media das temperaturas minimas é de $7^{\circ}, 4$ e a das maximas $19^{\circ}, 5$, em Guarapuava ellas eram, respectivamente, $11^{\circ}, 6$ e $22^{\circ}, 4$ no periodo de $1921-1925$ e $11^{\circ}, 5$ e $22^{\circ}, 5$ no periodo de $1885-1889$, o que nos faz crer que não tem havido alteração na temperatura do logar, pelo menos nos quarenta ultimos annos.

Em Campos do Jordão formam-se 57 geadas por anno; a estação climatologica de Guarapuava apenas accusa 15.

Em Guarapuava registaram-se, em 1922, 113 dias de chuva; em 1923, 128; em 1924, 92; e em 1925, 112 - média, 111. Em Campos do Jordão registam-se 127; em Davos-Platz, 140 (contados os de neve); em São Paulo, 142.

A pressão barometrica, que nos meses de inverno é normalmente mais alta, revelou a excellente variação de $18,8 \mathrm{~mm}$. Mas em DavosPlatz já ascende a mais de $40 \mathrm{~mm}$. Em São Paulo attinge $21 \mathrm{~mm}$. e em Botucatú 24,4 mm.

Vejamos agora a situação de Guarapuava em relação a outras cidades do Paraná.

Curityba, situada a 908 metros de altitude, com uma temperatura media de alguns decimos de grau mais elevada, apresenta amplitude thermometrica um pouco maior (média das maximas, $33^{\circ}, 7$; média das minimas, $-4^{\circ}, 3$, donde $38^{\circ}$ ) e offerece uma vantagem pequena na amplitude barometrica, que é de $18,2 \mathrm{~mm}$. A sua nebulosidade é maior $(6,4)$ e a insolação muito menor, pois apenas attinge a 1.910 horas (Guarapuava accusa a media de 2.369,28 em cinco annos). Se o vento, em Curityba, dá apenas uma velocidade media de 2,9 metros por segundo (3,48 em Guarapuava), já quanto á humidade é patente a inferioridade da nossa capital: $81,7 \%$ contra 76,38 \% de Guarapuava, onde, comtudo, cáe maior quantidade de chuva $(1.683 \mathrm{~mm}$. contra 1.452 de Curityba).

Em Palmeira, a 852 metros de altitude, com apenas 72 dias de chuva, a humidade attinge $79,4 \%$ ou seja mais $3,02 \%$ do que em Guarapuava. 
Ponta Grossa, a 947 metros acima do nivel do mar, é mais humida do que Guarapuava, pois apresenta a media de $79 \%$ de humidade relativa.

Palmas, em altitude mais elevada ( 1.155 metros) accusa uma amplitude barometrica de apenas $16,9 \mathrm{~mm}$. Entretanto as suas oscillações de temperatura são muito maiores, levando a amplitude a $43^{\circ}$ (maxima $35^{\circ}$ e minima $-8^{\circ}$ ) ou seja mais $5^{\circ} .7$ do que em Guarapuava. Cáe chuva em maior quantidade $(2.048 \mathrm{~mm}$. em 146 dias), elevando-se a humidade a $84,7 \%$ ou $8,32 \%$ mais do que em Guarapuava. Além disso, o clima de Palmas é mais frio, registando-se lá uma media annual de 40 geadas (a de Guarapuava approxima-se de 15). No triennio 1887-1889, a estação climatologica de Palmas registou 4 neves, emquanto que a de Guarapuava só observou uma unica.

\section{LABORATORIO DE CHIMICA, MICROSCOPIA E BIOLOGIA CLINICAS}

ANALYSES EM GERAL - VACCINOTHERAPIA

DR. OSCAR M. DE BARROS

RUA DIREITA, 25 - 1.0 andar

Caixa Postal, 1600
DR. MENDONÇA CORTEZ

Telephone : Central, 5033

S Ã O P A U L O 